\title{
Ecuador: ¿por qué salir de la dolarización?
}

\author{
Gonzalo J. Paredes
}

\section{Resumen}

La dolarización es un régimen monetario que obstaculiza el crecimiento sostenido y la capacidad de enfrentar perturbaciones externas sucesivas. Bajo esa premisa, se exponen cinco razones por las que convendría que el Ecuador saliera de la dolarización. Trabajos como los de Naranjo y Naranjo (2011), Acosta (2004), Correa (2004a y 2004b), Naranjo (2004) y Jameson (2003) fueron aportes valiosos y singulares a esta discusión, pero la bonanza petrolera y el cambio del modo de desarrollo en la última década han contribuido a que el debate quede cada vez más desierto. En este artículo se hace referencia a la teoría de la regulación y a la crisis argentina de 2001. Se concluye que la dolarización se ha mantenido por la transformación del modo de regulación que ha encauzado un régimen de acumulación distinto, pero que es necesaria la recuperación de la moneda nacional para consolidar el nuevo modo de desarrollo.

\section{Palabras clave}

Dólar, sistemas monetarios, política monetaria, crecimiento económico, Ecuador

Clasificación JEL

E510, F45, O54

Autor

Gonzalo J. Paredes es Doctorando de la Universidad Nacional de Córdoba (UNC) (Facultad de Ciencias Económicas (FCE)), Investigador del Instituto de Investigaciones Económicas y Políticas de la Universidad de Guayaquil (UG) y Docente de la Universidad Católica de Santiago de Guayaquil (USCG), Ecuador. gonzalo.paredes01@cu.ucsg.edu.ec 


\section{Introducción ${ }^{1}$}

Tras 15 años de vigencia de la dolarización, el sistema monetario del Ecuador se ha vuelto intocable. La clase dirigente financiera y económica asegura que la estabilidad económica que ha experimentado la sociedad ecuatoriana se debe al hecho de mantener al dólar como moneda nacional. Sin embargo, los avances de las ciencias económicas, que colocan al ser humano como eje de la sociedad, y la experiencia de uno de los mayores fracasos del neoliberalismo en América Latina, ponen en evidencia la inconsistencia de esa afirmación.

En la Argentina, la convertibilidad impidió disponer de dinero interno más allá del dólar y fue la razón fundamental de la prolongada recesión y el creciente endeudamiento que pesaron sobre la economía argentina, al punto de destruir los circuitos productivos internos. Se trata de una experiencia análoga a la de un Ecuador sin moneda propia.

Según Keifman (2004), las lecciones de la experiencia argentina son las siguientes: i) los regímenes monetarios rígidos son insostenibles; ii) mientras duran, solo aseguran la estabilidad de precios; iii) tienen altos costos sociales; iv) tales costos son mayores cuanto mayor es su duración, y v) los efectos distributivos de una salida caótica pueden ser muy elevados.

La idea de que la dolarización ecuatoriana no se asemeja en nada a la convertibilidad tuvo una exitosa difusión mediática, política y académica. Un país que experimenta su segundo boom petrolero e intenta de nuevo emprender un desarrollo acelerado reedita la premisa del centro financiero bonaerense de los años noventa de que "el régimen no se toca". Eso significaría que al final del camino existiría un desenlace idéntico. Desde la visión más ortodoxa de la economía se afirma que la dolarización solo es sostenible si el gasto público crece a una tasa muy baja (y constante) y el Estado no tiene un peso más allá de una quinta parte del producto interno bruto (PIB). Muchas veces, la focalización excesiva en algún objetivo de política, por ejemplo la preservación del dólar como moneda nacional, se convierte en un fin prioritario de la economía, lo que resta espacio a otros aspectos igualmente importantes del desarrollo.

En los años 2000, en el Ecuador, acoplar las condiciones externas favorables al desarrollo económico tan postergado no era una cuestión de elección. Era el compromiso de un proceso social impulsado por una realidad lacerante. Restablecer la política cambiaria y monetaria era afianzar ese proceso social y la senda hacia el desarrollo. Por tal motivo, las razones para justificar una posible salida de la dolarización son múltiples. Solo la teoría de la regulación, con su vocación pluridisciplinaria, puede ayudar a clarificar las peligrosas trampas y colapsos, tal como señala Carrera (2004). La teoría clásica, con su concepción de que el dinero es neutral, no ha alcanzado a explicar la crisis argentina de 2001, ni alcanzaría para demostrar que el inestable crecimiento económico del Ecuador en la década de 2000 (incluida la recesión que aqueja al país en el momento de terminar de escribir este trabajo) se debe a la insistencia de mantener al dólar como moneda nacional.

El presente artículo se estructura de la siguiente manera: a continuación de la Introducción, en la sección II, se analiza la economía política de la pérdida de la soberanía monetaria, mientras que en la sección III se esgrimen cinco razones para abandonar la dolarización en el Ecuador. Por último, en la sección IV, se presenta un conjunto de conclusiones y reflexiones finales.

\footnotetext{
1 El autor expresa su reconocimiento a Noemí Brenta (Facultad de Ciencias Económicas (FCE)-Universidad de Buenos Aires (UBA)), Marina Mero (Facultad de Ciencias Económicas (FCE)-Universidad de Guayaquil (UG)), M. Teresa Alcívar y M. Josefina Alcívar (Facultad de Especialidades Empresariales (FEE)-Universidad Católica de Santiago de Guayaquil (UCSG)) por sus valiosas contribuciones al presente trabajo.
} 


\section{La economía política de la pérdida de la soberanía monetaria}

A fines del siglo XX, el Ecuador sufrió una de las crisis más profundas de su historia. A todas luces fue una crisis bancaria originada en la aplicación de la Ley General de Instituciones del Sistema Financiero (LGISF), que respondía a dos clases de rivalidad: la geográfica y la pugna por el poder monopólico (dentro y fuera del sector bancario).

Se presentó a la LGISF como una norma que reestructuraba el negocio bancario en su conjunto, pero terminó propiciando la autodepuración del sector. Al liberalizar los negocios bancarios, incapacitar a la Superintendencia de Bancos en su gestión de control, formalizar los grupos financieros y permitir los créditos vinculados hasta el $60 \%$ del patrimonio técnico de los otorgantes, contribuyó a que todo el sistema financiero fuera más susceptible a la corrupción (Falconí y Oleas, 2004; Miño, 2008).

Los bancos que no incurrieron en prácticas dañinas y, a la vez, pugnaron por captar una mayor proporción del mercado, dado que eran catalogados como medianos, obtuvieron como "recompensa" no solo la capacidad de formar un oligopolio para captar y colocar dinero, sino también para manejar la liquidez monetaria, mediante la pérdida de la soberanía monetaria².

En el camino hacia la autodepuración del sector se eliminó una de las principales características del sistema establecidas durante el auge del neoliberalismo en el Ecuador: la independencia del Banco Central del Ecuador. Esa independencia se hallaba consagrada en la Constitución Política de la República del Ecuador de 1998 y posteriormente se plasmó en la Ley Orgánica de Régimen Monetario y Banco del Estado. Sin embargo, esa misma Constitución, en su disposición transitoria núm. 42, estableció que el Banco Central podría "otorgar créditos de estabilidad y de solvencia a las instituciones financieras, así como créditos para atender el derecho de preferencia de las personas naturales depositantes en las instituciones que entren en proceso de liquidación". De ese modo se consagró a nivel constitucional el riesgo moral y se destruyó la independencia del Banco Central (Oleas, 2001).

Stiglitz (2012), al preguntarse cómo es posible que los sectores financieros consigan acumular tanta riqueza, sostiene que una parte de la respuesta es muy sencilla, y ella es que dichos sectores han ayudado a redactar un conjunto de normas que les permite hacer grandes negocios, incluso durante las crisis que han contribuido a crear. El planteamiento anterior refleja el propósito de la LGISF. Esta ley, que permitió la autodepuración del sector, trasladó el eje financiero-geográfico de Guayaquil a Quito. Instituciones financieras consideradas medianas y pequeñas pasaron a dominar el negocio bancario y, con la dolarización, también la llamada liquidez monetaria de la economía (véase el gráfico 1$)^{3}$.

\footnotetext{
2 Según cifras de la Superintendencia de Bancos, en diciembre de 1993, los bancos considerados grandes eran el Filanbanco y el Banco del Pacifico, con el $13,81 \%$ y el $13,21 \%$ de los activos totales, respectivamente. Los medianos eran el Banco Pichincha, el Banco del Progreso y el Banco Guayaquil, con el 10,2\%, el 7,62\% y el 5,34\%, respectivamente. Los pequeños eran La Previsora y Produbanco. En diciembre de 1998, el Banco del Pacífico había perdido terreno en el sector en favor del Banco del Progreso, que en menos de tres meses estaría envuelto en problemas de corrupción.

3 En su columna de opinión del 11 de agosto de 2013 en el diario El Universo, Walter Spurrier señala lo siguiente: "Los efectos de la crisis bancaria se evidencian en las cifras de la producción. Hacia fines del siglo XX Guayaquil era la indiscutible capital financiera. Hoy, una de las mayores brechas entre las dos plazas es que el valor agregado financiero de Quito es $46,2 \%$, más del doble que Guayaquil, con 21,2\%" (Spurrier, 2013). Véase [en línea] http://www.eluniverso.com/opinion/2013/08/11/ nota/1269991/economias-guayaquil-quito. Baste mencionar que el Banco Pichincha, que en diciembre de 1998 tenía el 10,86\% del total de los activos, en diciembre de 2002 tenía el 27\% de ellos. En esa misma fecha, Produbanco tenía el 10,81\% de los activos totales del sistema, mientras que en diciembre de 1998 era un banco pequeño, con un 3,84\% de los activos.
} 
Gráfico 1

Ecuador: liquidez total, enero de 2007 a abril de $2016^{a}$

(En millones de dólares)

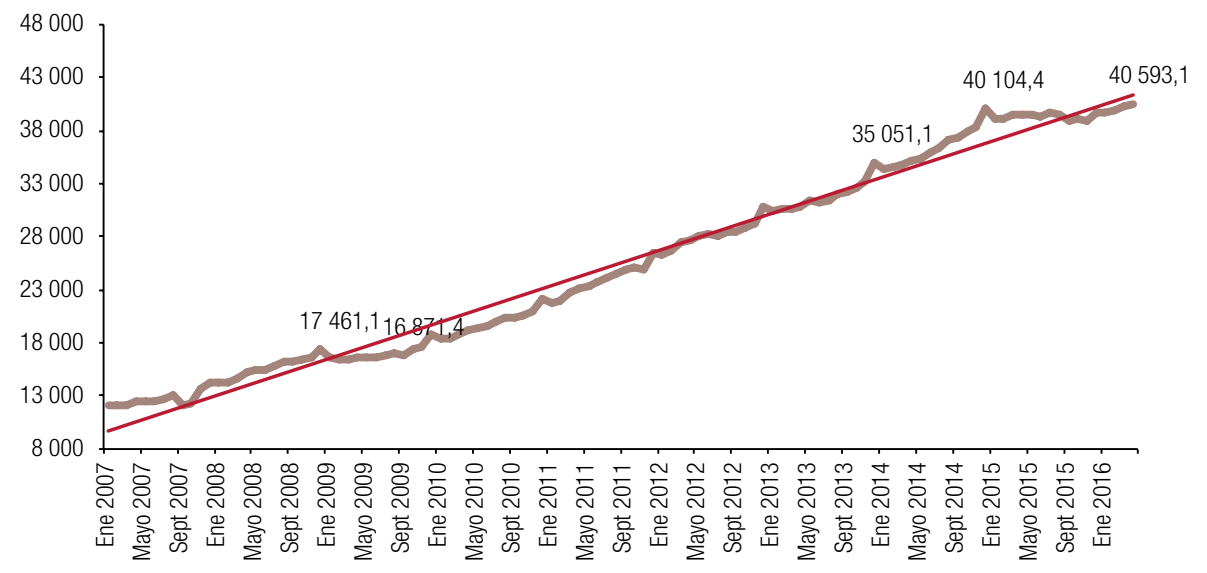

Fuente: Elaboración propia, sobre la base de Banco Central del Ecuador, Información Estadística Mensual, № 1971, Quito, 2016.

a La liquidez total o dinero en sentido amplio incluye la oferta monetaria y el cuasidinero.

La base monetaria, que antes de enero de 2000 se originaba y manejaba en el Banco Central del Ecuador por su capacidad de emisión, ahora proviene del sector externo y es administrada por el sector bancario en su rol de intermediador. Además, al no haber un banco central con capacidad para gestionar las políticas monetaria, crediticia y financiera, la banca privada está completamente a cargo de la creación de dinero bancario.

La crisis bancaria de 1999 y la pérdida de la soberanía monetaria abrieron la puerta a una nueva etapa del pensamiento dominante en los años noventa en el Ecuador: la recomposición neoliberal, que propugnó por todos los medios posibles las bondades de la dolarización y los riesgos que entrañaría abandonarla. Además, promovió condiciones tan favorables como insuperables para el negocio bancario, caracterizadas por el comportamiento alcista del precio del petróleo, el aumento de flujos de remesas de los migrantes, un Estado con una elevada deuda social y completamente desorganizado administrativa y fiscalmente, y la autorregulación.

La crisis de 1999 impuso varias reformas a la supervisión bancaria. No obstante, se mantuvo intacta la capacidad del sector de fijar el precio de las operaciones activas y pasivas y de los servicios financieros, de crear su propio "fondo de liquidez" en bancos en el exterior, de definir la orientación y asignación de los créditos y, sobre todo, de mantener la libre transferencia de divisas, desde y hacia el exterior. En ese escenario excepcional, durante todo el período de la dolarización, la banca ha obtenido cuantiosas ganancias que la han transformado en uno de los sectores más rentables y prósperos de la economía ecuatoriana. 


\section{Cinco razones para abandonar la dolarización en el Ecuador}

\section{Antecedentes de la política cambiaria del Ecuador}

La crisis argentina de 2001 (tanto su desarrollo como su salida) es una experiencia análoga a la de un Ecuador que carece de soberanía monetaria ${ }^{4}$. La convertibilidad (currency board) y la dolarización pertenecen a las integraciones monetarias pasivas caracterizadas por abandonar la toma de decisiones sobre la política monetaria, crediticia y cambiaria al integrarse a una moneda de un país o una zona monetaria (Cuevas, 2002; Paredes, 2015) ${ }^{5}$. En esas integraciones, los factores que determinan la cantidad de dinero son endógenos y la restricción monetaria se vuelve mucho más difícil de manejar.

En el Ecuador, la cantidad de dinero depende del comercio exterior. En la Argentina, estaba subordinada a los flujos de capital dado el contexto internacional en que nació el plan. Así, cuando los capitales foráneos desaparecieron a partir de 1998, la base monetaria comenzó un proceso de contracción que se transmitió al sistema crediticio y, tiempo después, a todo el sistema de pagos.

Debido a los efectos de la crisis financiera internacional de 2008-2009, transmitidos al Ecuador por el canal comercial, la base monetaria también se redujo (844 millones de dólares entre diciembre de 2008 y mayo de 2009). Ello supuso un deterioro de la situación del mercado laboral y frenó los avances conseguidos en los 24 meses anteriores en materia de distribución del ingreso, pobreza e indigencia (véase el gráfico 2) (Paredes, 2015) ${ }^{6}$.

Gráfico 2

Ecuador: base monetaria, enero de 2007 a abril de $2016^{\text {a }}$

(En millones de dólares)

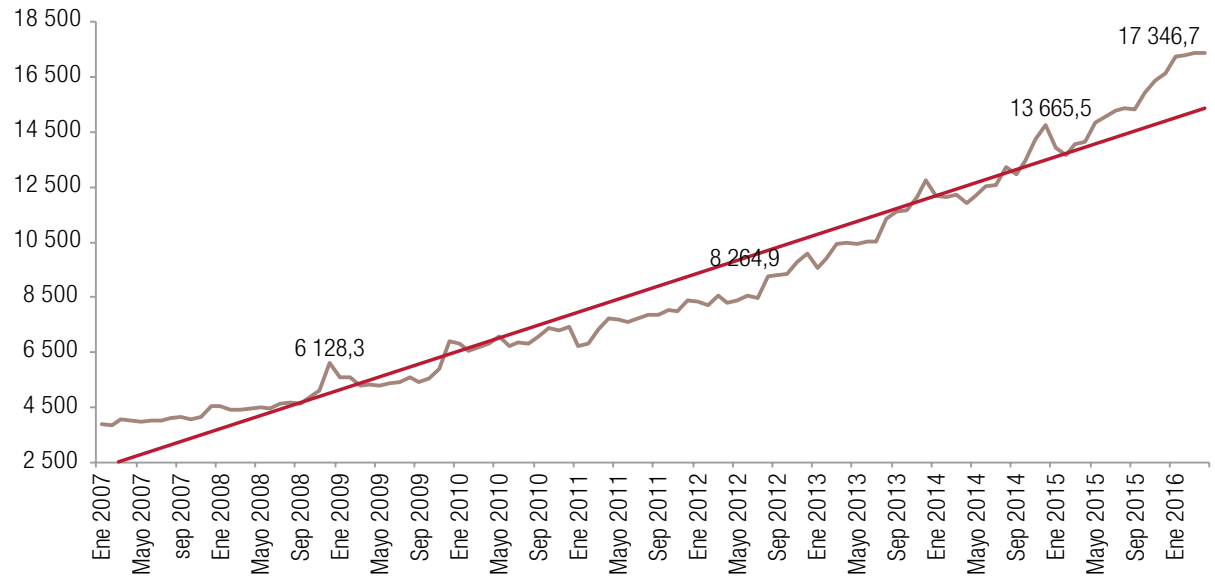

Fuente: Elaboración propia, sobre la base de Banco Central del Ecuador, Información Estadística Mensual, № 1971, Quito, 2016.

a La base monetaria o dinero de alto poder se define contablemente como la suma de la emisión monetaria y las reservas bancarias. En el sistema de dolarización se consideran las especies monetarias en circulación, las cajas del sistema bancario (Banco Central del Ecuador (BCE) y otras sociedades de depósito ) y las reservas bancarias en el BCE.

4 Pocas semanas después del abandono de la convertibilidad en la Argentina, las alertas se encendieron en el Ecuador en debates y foros. La revista Gestión, especializada en temas de economía y sociedad, en su edición № 92 de febrero de 2002, planteó como tema central: ¿es la dolarización una bomba de tiempo?

5 Martirena-Mantel (2003, pág. 97) expresa que la dolarización en el Ecuador, categorizada como unilateral (a pesar de implicar también una moneda única), no respeta necesariamente la teoría de área monetaria óptima de Robert Mundell.

6 El mercado laboral es un espacio estratégico para confrontar la desigualdad y la inequidad económica (Sánchez, 2011). Allí es también donde se canalizan, reproducen y amplifican las perturbaciones externas, en particular si se trata de un mercado laboral como el ecuatoriano, donde la tasa de subempleo es muy alta. La heterogeneidad estructural, según Fuentes (2014) y CEPAL (2012c), está relacionada con una marcada segmentación del mercado laboral. 
La convertibilidad se implementó en la Argentina sobre la base de cuatro pilares: i) la promesa de que no existiría la intervención de un poder colectivo; ii) la paridad 1 a 1, que serviría para mantener estable el sistema de cuentas y el buen funcionamiento de los pagos; iii) los argumentos de legitimidad como, por ejemplo, quitarle al banco central la capacidad de manejar a discreción la cantidad de dinero en la economía, y iv) la idea de que sería imposible construir un régimen monetario alternativo ${ }^{7}$.

En ese contexto, la incapacidad del Estado de contar con instrumentos eficaces que le permitieran mantener la economía en su plena capacidad, las falsas promesas de paridad 1 a 1 , el concepto de que la inflación era un fenómeno puramente monetario, y la fuerza política de la clase dirigente financiera y económica para imponer sus ideas, llevaron a la Argentina, la segunda economía más grande de América del Sur, a la más profunda recesión, con graves daños sociales intergeneracionales.

El crecimiento económico y la recuperación de los ingresos entre 1990 y 1994 fueron inequitativos: el decil superior registró un ingreso real por encima del que tenía en 1980. La evolución posterior a 1994 fue claramente regresiva. Se deterioraron los ingresos del 60\% de los hogares con ingresos más bajos y mejoraron los de los tres deciles superiores. Es decir, la situación distributiva a fines del siglo XX representó, en términos reales, una notable regresión con respecto a 1980 (Altimir, Beccaria y González, 2002).

De la Encuesta Permanente de Hogares (EPH) del Instituto Nacional de Estadística y Censos (INDEC) de la Argentina surge que, en mayo de 2001, un 26,2\% de los hogares estaba por debajo de la línea de la pobreza (en 28 aglomerados urbanos). Un año después, en mayo de 2002, esa cifra había pasado al 41,4\%, lo que muestra los efectos profundos que habían causado en ese período los severos ajustes de la política económica conducida por el entonces ministro Cavallo y su equipo de asesores para mantener la paridad 1 a 1. En el Gran Buenos Aires, durante el período señalado, la incidencia de la pobreza en los hogares era del $23,5 \%$. Un año después era del $37,7 \%$. Si se incluyen las ciudades más grandes, el número de hogares afectado por la pobreza se amplía, lo que demuestra que la regresión en la distribución del ingreso en las provincias era mucho más acentuada. Las condiciones sociales reflejaron el comportamiento del mercado de trabajo, el deterioro de bienes públicos como la salud y la educación, y la desarticulación de los tejidos productivos y sociales, principalmente en los grandes centros urbanos ${ }^{8}$.

Por ese motivo, Carrera (2004) afirma que la convertibilidad introdujo una transformación radical en el comportamiento del mercado laboral: el viejo patrón de los años ochenta, con niveles de desempleo estables relativos y que coexistían con salarios reales altamente variables, fue reemplazado en los años noventa por otro de características diametralmente opuestas. De forma análoga, la convertibilidad mostró resultados muy dispares: excepcionales en cuanto a crecimiento e inflación, pero negativos en cuanto al sector externo, el mercado laboral y la distribución del ingreso.

Dado lo antes expuesto, cabe preguntarse por qué los agentes económicos estaban convencidos de la viabilidad de la convertibilidad en el largo plazo. Se exponen tres razones: en primer lugar, Boyer (2007) afirma que el modelo se difundió en un marco de coherencia ideológica institucional que, según Wainer (2010), formaba parte de la articulación de las distintas facciones burguesas bajo la hegemonía del capital financiero.

\footnotetext{
7 La teoría de la regulación identifica esos pilares como "confianzas". Aglietta y Orléans, citados por Marques-Pereira (2007) afirman que la soberanía política del ejercicio monetario se sustenta mientras concurran las tres dimensiones de la confianza: metódica, jerárquica y ética. La primera se manifiesta en el buen funcionamiento de los pagos; la segunda, en la garantía de una autoridad, y la última se define por los criterios de legitimidad. Roig (2007) agrega una más: la confianza desesperada, que tiene dos efectos: i) tornar menos flexible la institución monetaria, lo que impide incorporar el cambio y transformarse, porque cualquier modificación de la forma monetaria pone en jaque su confianza, y ii) desactivar la política, es decir, impedirle todo tipo de acción sobre la economía y, a su vez, transformar la configuración de la responsabilidad política.

8 Ferrer (2004) define este escenario como "heterogeneidad estructural" y utiliza el concepto de "densidad nacional".
} 
En segundo lugar, Galiani, Heymann y Tomassi (2003), Heymann (2000) y Conesa (1996) plantean la hipótesis de los efectos esperados de la "densidad contractual". La estricta adherencia a la regla monetaria existente (sobre la base de un elaborado sistema de contratos, concertados en su mayoría en dólares) se identificó con estabilidad y previsibilidad. Para ello, el Gobierno (mediante la emisión de bonos denominados en dólares) y el sector privado (mediante la acumulación de grandes deudas y activos en dólares) hicieron que su solvencia dependiera del mantenimiento del tipo de cambio. El conjunto de promesas parecía tal que, o bien se cumplían todas juntas, o bien se rompían todas juntas. Cualquier salida del statu quo de "un peso-un dólar" generaría una perturbación de consecuencias impredecibles.

En tercer y último lugar, Roig (2007) elaboró la hipótesis sobre el modo en que la producción de conocimiento, en particular el económico, influyó en el funcionamiento de la convertibilidad y su crisis ${ }^{9}$. Ello permitió construir una forma específica de confianza catalogada como desesperada, en torno a la moneda, basada en la imposibilidad de salir del régimen monetario establecido. El autor señala que dicha imposibilidad no se apoya solamente en el hecho de afirmar que algo es imposible, sino principalmente de desautorizar la posibilidad de que existan alternativas.

Las tres razones expuestas de la viabilidad no son divergentes entre sí, sino todo lo contrario. La imposibilidad se sustentó en el llamado "miedo a flotar", proveniente de la elaborada forma contractual de la convertibilidad y de la coherencia ideológica institucional, tan difundida por los medios periodísticos y el sector académico. La convergencia era posible porque el régimen monetario amplificaba la concesión de rentas.

\section{La restricción monetaria estricta es altamente vulnerable ante las perturbaciones externas persistentes}

El dinero opera como eje de las relaciones de intercambio, que pasan por la intermediación del dinero. Eso es lo que se conoce como restricción monetaria. De esa idea se concluye que la realización de las mercancías está sujeta a la disponibilidad de dinero en la economía (Aglietta, 1979).

La dependencia del capitalismo con respecto a la circulación mercantil se expresa por las relaciones de equivalencia en el intercambio. La restricción monetaria no es una referencia permanente y absoluta, sino que depende de la manera en que se forme el equivalente general. Los bancos experimentan la restricción monetaria respecto a la sociedad en su conjunto, porque son responsables de la conversión, en cualquier momento y sin limitación alguna, de los distintos dineros bancarios en dinero-mercancía. Esa conversión general y permanente es la prueba de que el dinero bancario posee los atributos de su equivalente general.

Para Aglietta (1979), cualquier crisis de realización del valor de cambio adquiere un carácter global y se presenta como una crisis financiera. Ello concierne a toda la circulación financiera, pero el epicentro de la crisis es necesariamente el sistema bancario, que es el lugar de movilización de las deudas privadas. Así pues, el papel del banco central consiste en organizar el proceso de convertibilidad del dinero bancario, manipulando la emisión de su propio dinero.

La implementación de la convertibilidad coincidió con el auge de los flujos de capital en los países emergentes. Dichos flujos fueron el principal sustento de ese régimen en los primeros años y tuvieron como principal destino el sistema financiero, lo que dio lugar a procesos bastante acentuados

\footnotetext{
9 Roig (2007) afirma que las lógicas de autorización se encuentran presentes en todas las profesiones y disciplinas, pero cobran una dimensión particular en las ciencias económicas. De las ciencias cercanas "al poder", esta es la que goza de mayor respeto, la que tiene un estatus de verdad que valida la autorización y que alcanza una mayor difusión en la sociedad, a través de la educación y los medios de comunicación.
} 
de creación de dinero bancario, que superaba sistemáticamente la masa monetaria. Cuando esos flujos se revertían, entraban en acción dos mecanismos de ajuste: uno era automático (la contracción de la base monetaria) y el otro se aplicaba cuando el primero no llegaba a funcionar (el ajuste fiscal).

Sin embargo, cuando los flujos de capital no eran positivos (llegaron a ser negativos por las fugas de capital) y no se podían obtener préstamos de organismos internacionales (el Fondo Monetario Internacional suspendió el apoyo a la Argentina, con lo que se instituyó el enfoque de Krueger-Rogoff de no intervención en las crisis financieras para evitar el riesgo moral), el aumento de la tasa de interés no fue suficiente para incentivar a los inversores internacionales. Fue entonces que entró en acción el ajuste fiscal para tratar de remediar la ausencia de los capitales externos por medio de una mayor contracción económica que condujera al aumento de la tasa de interés (a fin de incentivar el regreso de los capitales) y la disminución de los costos laborales para generar bienes transables más baratos.

El "ajuste del ajuste", realizado durante el gobierno del Presidente De la Rúa, no logró incentivar el regreso de las corrientes de capital ya que los desequilibrios económicos generados por la caja de conversión eran cada vez más evidentes. Simplemente no funcionó la idea de generar un superávit fiscal para pagar el servicio de la deuda externa mediante la reducción cada vez mayor del gasto corriente (FMl, 2004, pág. 43 y 2001, págs. 29 a 33).

La escasez monetaria que implicó la tensión sobre las reservas de divisas hizo explotar la pluralidad de unidades de cuenta generada por los efectos sociales y fiscales de la Ley de Convertibilidad (monedas sociales y títulos provinciales que circulan como moneda). Baldi-Delatte (2007) define esta situación como crisis monetaria, en que la ausencia de unanimidad sobre la utilización de una o varias monedas convertibles entre sí se manifiesta por la inestabilidad del sistema monetario, lo que a su vez lleva a una crisis económica ${ }^{10}$.

En el gráfico 3 se muestra la escasez monetaria (reducción de la base monetaria), que se profundiza en el segundo semestre de 2001 y en noviembre llega a ubicarse en 11.018 millones de pesos, cuando a finales de 2000 estaba por encima de los 15.000 millones de pesos. Es importante señalar que la cantidad de dinero (base monetaria) que circuló al final del primer auge de la convertibilidad (diciembre de 1994) fue de 16.049 millones de pesos, mientras que al final del segundo auge (diciembre de 1998) fue de 16.370 millones de pesos. En otras palabras, antes de la salida de la convertibilidad se había perdido casi una tercera parte de la base monetaria.

Gráfico 3

Argentina: base monetaria, diciembre de 2000 a junio de 2002

(En millones de pesos)

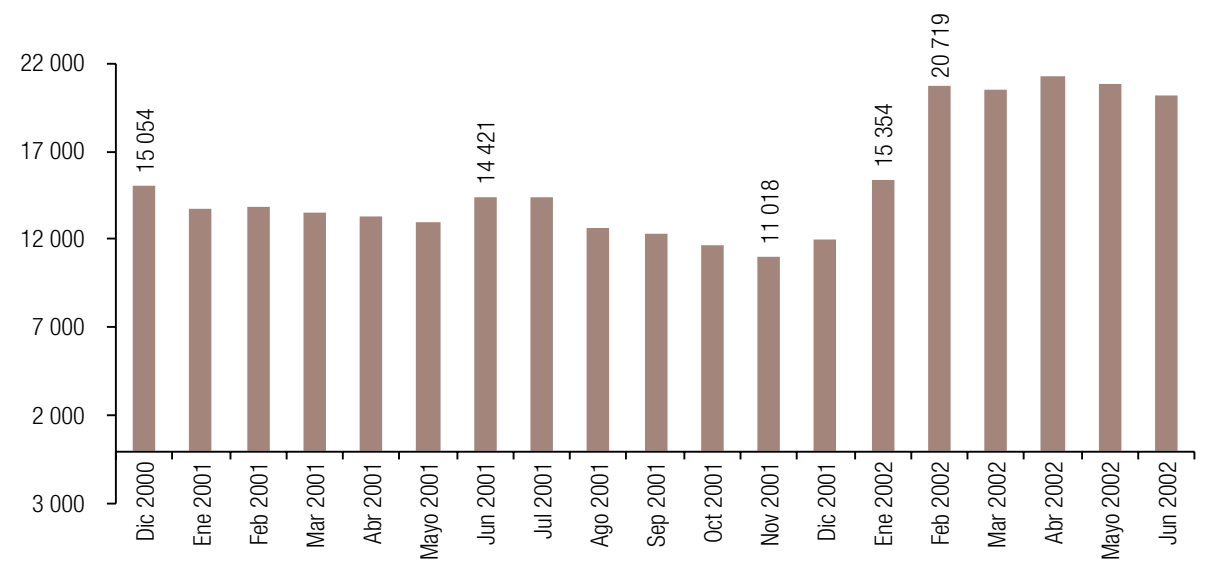

Fuente: Elaboración propia, sobre la base de cifras del Banco Central de la República Argentina (BCRA).

\footnotetext{
10 Se entiende por sistema monetario el conjunto de reglas que permiten declarar los precios, realizar las transacciones y definir las obligaciones para honrarlas.
} 
Como se mencionó anteriormente, la base monetaria del Ecuador también se redujo 844,10 millones de dólares durante la vigencia de la dolarización ${ }^{11}$. La situación fue acuciante entre diciembre de 2008 y mayo de 2009, período en que se registró una caída de cerca del 14\%. A diferencia del caso argentino, la base monetaria no siguió reduciéndose, sino que repuntó en los meses siguientes y, como pudo apreciarse en el gráfico 2, regresó al valor de diciembre de 2008 un año después.

Esa diferencia se debe a que el precio del petróleo tuvo un comportamiento alcista en el segundo semestre de 2009, pero sobre todo a que se crearon grados de política monetaria respecto de la dolarización a través de las políticas públicas. Los fundamentos de una economía sin moneda propia giran principalmente en torno a que el gobierno central ya no tiene la capacidad de imprimir dinero, aunque en un Estado organizado para cumplir su rol de controlar y regular sí tendría la capacidad de disponer del ahorro privado que se encuentra en bancos extranjeros (bajo la administración de instituciones financieras privadas radicadas en territorio nacional) y ponerlo al servicio de las urgentes necesidades de financiamiento de los agentes económicos del país.

En septiembre de 2009, el Gobierno nacional creó grados de política monetaria cuando, en virtud de una resolución del Banco Central del Ecuador, obligó a la banca privada a repatriar los ahorros de los depositantes que se encontraban en bancos extranjeros para dinamizar el crédito en el país. De esa forma, se evitó la agudización del fenómeno catalogado por Aglietta (1979) como restricción monetaria, ya que las políticas públicas y el escenario internacional, en ese orden, no lo permitieron.

Sin embargo, si en el Ecuador se hubiera mantenido una política de permanente austeridad fiscal, como la diseñada en los primeros años de la dolarización, combinada con una política bancaria de excesiva precaución en la garantía de los depósitos, se habría reducido marcadamente la base monetaria y, por tanto, las actividades productivas y comerciales no se hubieran desarrollado en su plena capacidad. Si la realización de las mercancías está sujeta a la disponibilidad de dinero en la economía (restricción monetaria), la agudización de la restricción significa una crisis de la realización, lo que no ocurrió en el Ecuador debido a la creación de grados de política monetaria respecto del régimen monetario. Fue una situación muy diferente a la ocurrida en la Argentina, país que, en medio de la profundización de la crisis, optó por ceñirse aún más al sistema de convertibilidad.

\section{3. ¿El nuevo modo de regulación o el régimen monetario?}

La teoría de la regulación propone entender el capitalismo (y sus crisis) desde un enfoque multidisciplinario. Esa comprensión permite establecer conceptos "intermedios" para explicar la forma de desarrollo de las economías capitalistas, a saber, el modo de regulación y el régimen de acumulación. El primero canaliza los comportamientos individuales y colectivos en función del régimen de acumulación, lo que permite la reproducción de las formas institucionales ${ }^{12}$.

Boyer y Saillard (1996) conceptualizan el régimen de acumulación como un conjunto de regularidades que aseguran un progreso general y relativamente coherente de la acumulación del capital, es decir, que permiten reabsorber o postergar las distorsiones y desequilibrios que se derivan permanentemente del propio proceso.

La articulación específica de un régimen de acumulación del capital y de un modo de regulación dentro de cada formación social dan lugar a la constitución de un modo de desarrollo. De acuerdo con la especificidad nacional y la manera en que pueden existir y sucederse diversos regímenes de acumulación y modos de regulación, los modos de desarrollo resultan bastantes diversos. Por consiguiente, las crisis del modo de desarrollo son resultado de las modificaciones que intervienen en los niveles del régimen de acumulación y del modo de regulación.

\footnotetext{
11 Una reducción que se aleja de fluctuaciones momentáneas o eventuales.

12 Las formas institucionales de un modo de regulación son cinco: i) la moneda o restricción monetaria; ii) el Estado; iii) la relación salarial; iv) las formas de competencia, y v) la inserción internacional.
} 
Desde el punto de vista de la teoría de la regulación, la transición de un modo de regulación a otro es posible como resultado de una transformación de las formas institucionales, así como de la emergencia de crisis planteadas en ese nivel. A menudo provoca una modificación de los mecanismos y las regularidades económicas. La naturaleza y la dimensión de esas crisis son muy heterogéneas porque dependen de las estructuras económicas propias de cada formación social. Las nuevas formas institucionales específicas no surgen de manera mecánica o fatal, ni están necesariamente predeterminadas por el régimen de acumulación. Su emergencia y la consolidación de su configuración pueden tomar cierto tiempo y el resultado final pone de manifiesto la correlación de fuerzas y las estrategias y objetivos de los actores sociales involucrados.

Según esa teoría, se puede afirmar que el causante de la estabilidad económica del Ecuador no es el régimen monetario llamado dolarización ni el dólar ${ }^{13}$. La estabilidad se origina más bien en la formación de un nuevo modo de regulación (tal como ocurrió en la posconvertibilidad) que ha desembocado en un modo de desarrollo distinto.

El objetivo de describir las formas institucionales y sus transformaciones es demostrar que el crecimiento económico de la última década no hubiera sido posible si no se desbarataba toda la estructura diseñada en la recomposición neoliberal. Cuando la transformación del Estado es radical, conlleva reacciones en cadena que también afectan a las demás formas institucionales ${ }^{14}$.

La crisis financiera internacional que estalló en septiembre de 2008, la constricción de la política fiscal y la ausencia total de política monetaria habrían llevado a la economía a una profunda recesión. Bajo esa premisa, el modo de regulación se encuentra en una etapa de transición que culminaría cuando se abandone la dolarización. La transición del modo de regulación se expresa en los cambios de las formas institucionales que se describen en el cuadro 1.

Cuadro 1

Ecuador: cambio de las formas institucionales, 2000-2006 y 2007-2015

\begin{tabular}{|c|c|c|}
\hline & $2000-2006$ & 2007-2015 \\
\hline \multirow{4}{*}{ 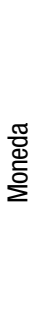 } & \multirow{4}{*}{$\begin{array}{l}\text { Plena circulación de las divisas internacionales en el país y } \\
\text { su libre transferibilidad al exterior, sobre la base de la Ley } \\
\text { de Transformación Económica del Ecuador de } 13 \text { de marzo } \\
\text { de } 2000 \text { (normativa que dio vigencia a la dolarización). } \\
\text { Inexistencia de un prestamista de última instancia. } \\
\text { Los ahorros administrados por el Banco Central del Ecuador } \\
\text { y el sistema financiero privado fueron depositados en } \\
\text { bancos del exterior o invertidos en papeles. El ahorro } \\
\text { del conjunto de la economía no servía para apuntalar } \\
\text { el desarrollo del país, sino el de países extranjeros, y el } \\
\text { aumento de utilidades. }\end{array}$} & $\begin{array}{l}\text { Las políticas públicas buscan maximizar la repatriación de divisas, minimizar } \\
\text { su salida y fortalecer el ahorro y la inversión interna. }\end{array}$ \\
\hline & & $\begin{array}{l}\text { En } 2008 \text { se creó una red de seguridad financiera que no afectara el riesgo } \\
\text { moral de las actividades bancarias. }\end{array}$ \\
\hline & & $\begin{array}{l}\text { Se evidenció la falsedad (de origen ideológico) de la inexistencia de política } \\
\text { monetaria en la dolarización. }\end{array}$ \\
\hline & & $\begin{array}{l}\text { Se fortaleció la institucionalidad del Estado sobre las actividades financieras } \\
\text { por medio de la creación de la Junta de Política y Regulación Monetaria y } \\
\text { Financiera con } 54 \text { funciones. }\end{array}$ \\
\hline
\end{tabular}

\footnotetext{
${ }^{13}$ Gabriela Calderón, en su columna publicada por el Cato Institute y en el diario El Universo, titulada "Dolarización: ser y parecer", afirma: "La dolarización no se mantiene, como se repite a diario en la prensa, por la reserva monetaria, los altos ingresos petroleros o las remesas de los migrantes. Se mantiene gracias a la voluntad de los ecuatorianos de realizar sus transacciones en esta moneda siendo también necesario que los que administran el Estado adopten una estricta disciplina fiscal y políticas que fomenten la inversión nacional y extranjera" (Calderón, 2009).

${ }^{14}$ En la teoría de la regulación subyace la idea de que las instituciones representan compromisos sociales que se pueden considerar compromisos sociopolíticos. Detrás de cada institución existe un conflicto que busca ser resuelto. Las instituciones precisan una cierta relación de fuerzas y establecen una jerarquía, con sus consecuencias sobre la distribución del ingreso y del poder, entre otras cosas. El rol de la acción pública, del Estado, puede consistir en favorecer o no la emergencia de ciertos compromisos. Véase un estudio más a fondo de la complementariedad institucional en Amable (2007).
} 
2000-2006

La reducción del papel del Estado en la economía comenzó de forma simultánea con la crisis de la deuda, que se agudizó en los años noventa, y posteriormente con la quiebra del sistema bancario. Durante años, el Estado ecuatoriano relegó al sector social por el servicio de la deuda externa y por ser "garante" del $100 \%$ de los depósitos bancarios. A partir de 2000, el Estado fue sometido a un sinnúmero de restricciones fiscales basadas en las experiencias de la Argentina y Chile. La mayor política de austeridad implementada durante el período de la dolarización tuvo lugar entre 2003 y 2005, mediante el decreto de 22 de enero de 2003 y la carta de intención (acuerdo de derecho especial de giro), firmada por el Gobierno el 10 de febrero de 2003 en Washington, D.C. (véase [en línea] http:// www.imf.org/external/np/loi/2003/ecu/01/index.htm).

Los fondos de contingencias, creados sobre la base de varias normativas, sirvieron para asegurar el pago de la deuda externa.

Menor peso y presencia en la economía (20,42\% del PIB en 2004, el punto más bajo del período de la dolarización).

La Ley de Transformación Económica estableció la contratación por horas, modalidad que podría aplicarse hasta al $75 \%$ de los trabajadores de una empresa.

La desaparición del Estado en todos los ámbitos de la sociedad se sintió con más fuerza en el mercado laboral, donde los entes reguladores perdieron toda capacidad - de acción para proteger a los trabajadores de la clase empresarial.

ङ Dado lo anterior, en ese período la precarización laboral :등 es la regla, más que la excepción.

Dependencia del sector fiscal y externo de un activo del Estado: el petróleo. En 2004 representaba un 30,08\% de los ingresos totales del gobierno central y un $54,61 \%$ de las exportaciones totales.

Prevalece el canal comercial sobre el financiero. Existe mayor influencia sobre el sector fiscal y el sector externo de las variaciones de los precios de los bienes transables que de las tasas de interés internacionales.

Durante el período, el crecimiento medio de las importaciones fue de un $21,20 \%$.

Las importaciones de combustibles pasaron de 243,84 millones de dólares a 2.541,34 millones de dólares.
Reorganización burocrática y reinstitucionalización.

Incumplimiento y renegociación de la deuda comercial en diciembre 2008. La transformación del Estado, emprendida en 2007, eliminó los cimientos sobre los que se creó la dolarización (reacciones en cadena).

Mayor peso y presencia en la economía (un 44,04\% del producto interno bruto en 2013).

Recuperación de la soberanía sobre la política económica.

Después de la derogación de los fondos petroleros en febrero 2008 por parte de la Asamblea Constituyente, en octubre de 2010 la Asamblea Nacional aprobó el Código Orgánico de Planificación y Finanzas Públicas por el que se derogaron leyes de la época neoliberal: la Ley Orgánica de Administración Financiera y Control, la Ley Orgánica de Responsabilidad, Estabilización y Transparencia Fiscal, la Ley Orgánica para la Recuperación del Uso de los Recursos Petroleros del Estado y Racionalización Administrativa de los Procesos de Endeudamiento, la Ley de Presupuestos del Sector Público y el Capítulo I de la Ley de Regulación Económica y Control del Gasto Público.

La única regla fiscal que existe actualmente en el Ecuador es que los gastos permanentes no deben superar los ingresos permanentes.

En 2015, se diseñó una estructura arancelaria para preservar la cantidad de dinero en la economía, ante perturbaciones externas como la apreciación del dólar y la caída del precio del petróleo. Además, en 2016 se fortaleció la institucionalidad para reducir la elusión fiscal, sobre todo en el impuesto a las herencias, legados y donaciones.

La contratación por horas y el auge de la tercerización y la intermediación laboral (sin ningún marco regulatorio hasta mayo de 2006) precarizaron la actividad laboral, lo que se contradecía con los convenios internacionales de trabajo e impedía la organización sindical y la contratación colectiva. Esa situación fue recogida por la Asamblea Constituyente de 2008 en el Mandato Constituyente núm. 8, conformado por siete artículos, cuatro disposiciones generales, cinco transitorias y tres disposiciones finales, en que se derogaban, especialmente, esas dos normativas legales.

La nueva forma de concebir el trabajo implicó la generación de condiciones dignas y justas para los trabajadores. Con ese fin, el Estado actúa a través de regulaciones y acciones que permiten el desarrollo de distintas formas de trabajo. Se estableció la figura del salario digno y el reconocimiento del trabajo en el hogar.

La recuperación del Estado y la soberanía sobre la política económica ha cambiado la correlación de fuerzas entre trabajadores y empresarios. No obstante, a partir de 2015, se ha puesto énfasis no solamente en las desigualdades de la relación capital-trabajo, sino también en la clase trabajadora. Para ello se puso tope a las utilidades distribuidas al trabajador que, en general, no podrán exceder de 24 salarios básicos unificados.

En 2013, el petróleo representaba el 22,93\% de los ingresos totales del gobierno central y el 56,78\% de las exportaciones totales. Al finalizar 2015, el peso del petróleo estaba en un 11,13\% y un 36,33\%, respectivamente. Se entrevé un acuerdo comercial con la Unión Europea, dados los tratados de libre comercio de Colombia y el Perú con ese bloque regional y con los Estados Unidos.

La inversión extranjera directa (IED) ha sido muy baja con respecto a la que ha recibido la región (CEPAL, 2012). Desde 2014 se identifica la entrada de IED en sectores estratégicos.

Hasta 2013, el crecimiento medio de las importaciones fue del $12,31 \%$. Los efectos de la estructura arancelaria antes mencionada se reflejan en la reducción de las importaciones un 22,64\% entre 2014 y 2015. Entre enero y abril de 2016 , la reducción es del $36,46 \%$ con respecto al mismo período del año anterior.

Las importaciones de combustibles pasan de 2.541,34 millones de dólares a 6.616,55 millones de dólares. En 2015, ese tipo de importaciones fue de 4.171,09 millones de dólares.

El proceso constituyente iniciado en noviembre de 2007 obligó al sector financiero a desligarse de empresas de otros sectores. En esa misma línea, la aprobación de la pregunta núm. 3 del referéndum y de la consulta popular del 7 de mayo de 2011 tuvo su impacto en los medios de comunicación. Se está debatiendo la aprobación de un impuesto mayor sobre las herencias, legados y donaciones.
Existió una "relación incestuosa" entre la banca, los medios de comunicación y los grandes grupos económicos, que se puso de manifiesto a partir de la crisis de fin de siglo. Dada la inexistencia de políticas de regulación y control, el nuevo eje financiero-geográfico entró en un fuerte proceso de concentración, donde principalmente la banca privada estableció sólidos lazos con sectores importadores, el monopolio de la opinión pública y la comunicación y el Estado.

Fuente: Elaboración propia, sobre la base de datos del Banco Central del Ecuador (BCE), Información Estadística Mensual, № 1971, Quito, 2016; y Comisión Económica para América Latina y el Caribe (CEPAL), Inversión Extranjera Directa en América Latina y el Caribe 2011 (LC/G.2538-P), Santiago, 2012. 
Para entender estos cambios, Marconi (2001, pág. 11) sostuvo que "la dolarización no es un simple modelo alternativo de gestión que puede ser estudiado con herramientas convencionales [...] debe ser interpretado principalmente a partir de la economía política, pues su concepción, su modalidad de aplicación y las personas escogidas para instrumentarla responden claramente a intereses de conocidos grupos económicos, con fuertes vínculos en los ámbitos políticos y sociales y en los medios de comunicación".

Sobre esa base, el régimen monetario no es el que brindó las condiciones necesarias de estabilidad económica para que el ingreso per cápita de la población aumentara y permitiera al país sortear la mayor crisis del capitalismo desde la Gran Depresión. Esto es así por dos razones: por una parte, los encargados de la formulación de la políica económica durante la recomposición neoliberal crearon tres fondos "de contingencia" que inhibían el crecimiento económico y hacían que la política fiscal fuese inutilizable en posibles recesiones, ya sea por factores internos o externos ${ }^{15}$. Por otra, la dolarización en sí inhibe el crecimiento económico, ya que deja al país sin política monetaria y cambiaria para movilizar el ahorro interno, expandir las exportaciones y sustituir importaciones, y enfrentar las perturbaciones externas.

El principal canal de transmisión de esas perturbaciones es el comercial ${ }^{16}$. Ello puede ocurrir en dos escenarios posibles: la caída del precio del petróleo y el colapso o auge de la economía estadounidense. Esos escenarios (juntos o por separado) truncarían el desarrollo acelerado que ha registrado el Ecuador en los últimos años. El régimen monetario actual permite que el efecto de las perturbaciones externas se transmita de forma más directa y con mucha más rapidez.

El colapso de la economía estadounidense tendría profundas repercusiones sobre la economía mundial, pues cortaría los flujos comerciales entre los países desarrollados y en desarrollo y deprimiría la demanda de los principales productos de exportación de América Latina, entre ellos el petróleo. Otro escenario posible es que la economía estadounidense opere a plena capacidad y con alta productividad, lo que haría posible el fortalecimiento del dólar.

El colapso de la economía estadounidense puede afectar a las exportaciones ecuatorianas tanto desde el punto de vista del precio como de los volúmenes, como ocurrió durante la crisis financiera internacional de 2008-2009. Desde el segundo semestre de 2011, con una débil recuperación de la economía estadounidense, pero sin los problemas de la periferia europea, el tipo de cambio real multilateral (TCRM) del Ecuador ha mostrado una tendencia a apreciarse hasta la actualidad, sin indicios de regresar a los niveles previos, independientemente del año base que se utilice para su cálculo (véanse los gráficos 4 y 5) ${ }^{17}$.

\footnotetext{
15 Se les llamaba "de contingencia" porque servirían para amortiguar posibles perturbaciones externas que llevan al ciclo económico a su fase descendente. No obstante, la forma de asignar esos fondos no hacía honor a su nombre. Los recursos provenientes de la venta de crudo pesado (el segundo fondo petrolero se creó el 25 de marzo de 2002; el primero, por la venta de crudo liviano, se creó en virtud de la Ley de Transformación Económica, de 13 de marzo de 2000) estaban destinados en un $70 \%$ a la recompra de deuda pública externa a valor de mercado (Paredes, 2015).

16 Según Coq (2007), el Plan de la Convertibilidad dependía de los flujos de capital dado que el comercio exterior hacia los Estados Unidos representaba solo el 16\% del total (en 2007 esa cifra se encontraba en el 7,44\%). Es decir, el canal financiero dominaba al comercial. Los efectos de las perturbaciones externas en las integraciones monetarias pasivas del Ecuador y la Argentina difieren en cuanto a su canal de transmisión. El anuncio del abandono de la moneda nacional en el Ecuador ocurrió en un contexto internacional en que los flujos de capital huían de los países emergentes debido a las sucesivas crisis financieras acontecidas hacia el final de la década de 1990. Cuando un país cede soberanía sobre su política monetaria, establece una relación de líder-seguidor.

17 El comportamiento del TCR en relación con los Estados Unidos tiene una marcada influencia sobre el TCRM, lo que pone de relieve el peso de la economía estadounidense y de sus ciclos económicos.
} 


\section{Gráfico 4}

Ecuador: tipo de cambio real multilateral y de los principales socios comerciales, enero de 2005 a agosto de $2013^{a, b}$

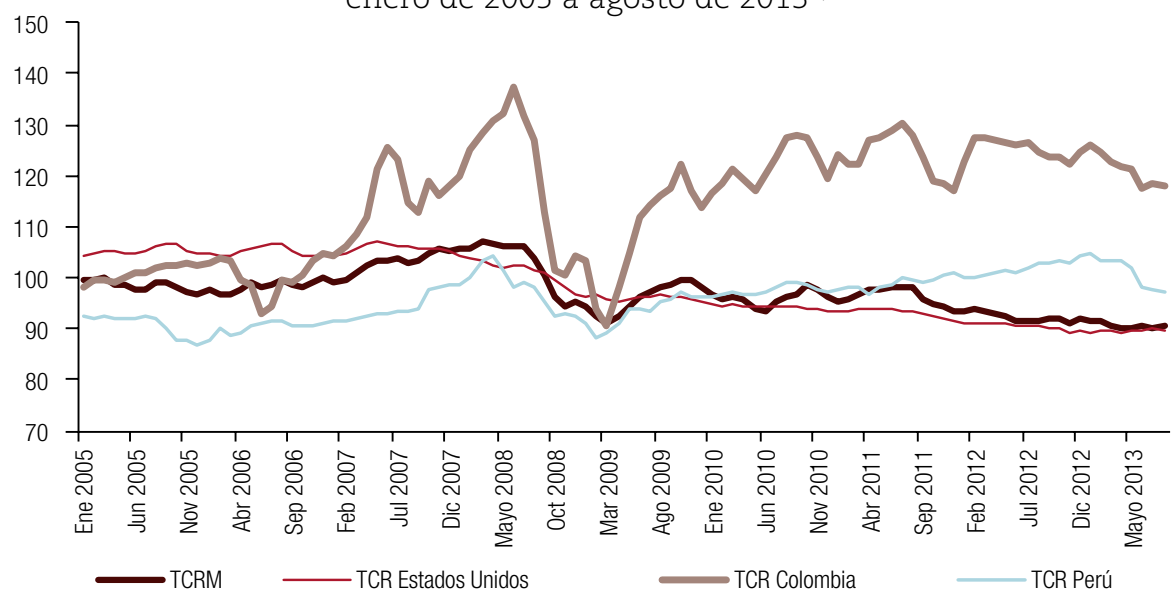

Fuente: Elaboración propia, sobre la base de datos del Banco Central del Ecuador (BCE), Información Estadística Mensual, № 1886, Quito, 2009; Información Estadística Mensual, № 1951, Quito, 2014.

a Año base 1994 = 100; TCR: Tipo de cambio real; TCRM: Tipo de cambio real multilateral.

b Se utiliza una muestra de los 18 países que tienen mayor comercio con el Ecuador, sin incluir el comercio de petróleo.

\section{Gráfico 5}

Ecuador: tipo de cambio real multilateral y de los principales socios comerciales, enero de 2012 a mayo de $2016^{a, b}$

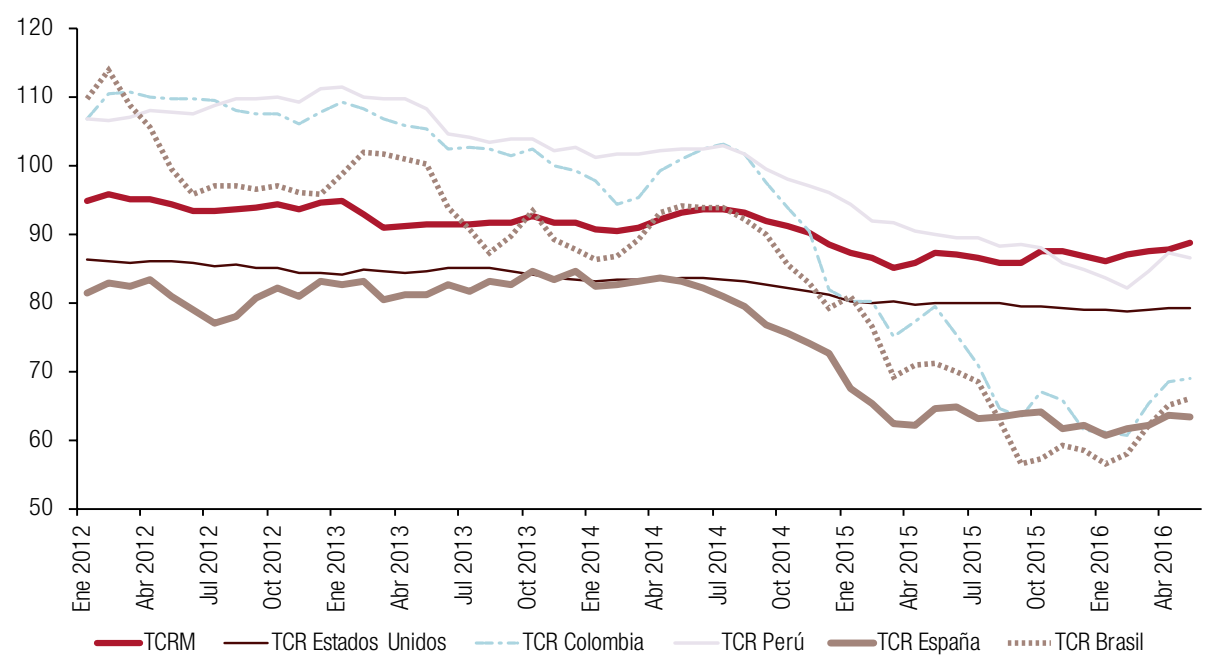

Fuente: Elaboración propia, sobre la base de datos del Banco Central del Ecuador (BCE), Información Estadística Mensual, No 1971, Quito, 2016.

a Año base $2007=100$; TCR: Tipo de cambio real; TCRM: Tipo de cambio real multilateral.

b Se utiliza una muestra de los 22 países que tienen mayor comercio con el Ecuador, sin incluir el comercio de petróleo.

Si por el lado de las exportaciones se vislumbra la dependencia del petróleo y la apreciación del tipo de cambio real, por el de las importaciones se señalan dos problemas estructurales: i) una demanda de importaciones muy elástica frente a las variaciones de la producción industrial y el crecimiento económico, y ii) la incapacidad de producir derivados del petróleo para satisfacer la demanda interna. 


\section{La dolarización inhibe la posibilidad de un crecimiento económico elevado y sostenido}

Se ha mencionado que las integraciones monetarias pasivas (la dolarización y la convertibilidad) tienen mucho éxito en la reducción de la inflación pero no en la institución de un esquema de crecimiento sostenido. En materia de políticas macroeconómicas, la Argentina de la posconvertibilidad se caracterizó por un tipo de cambio real competitivo y estable, la acumulación de reservas, la recuperación de los salarios reales y el control de la inflación (Heymann y Ramos, 2010).

Detrás de esas políticas estuvo el auge de los productos básicos, que resultó en un crecimiento elevado y sostenido de la economía que solo se vio socavado por la crisis financiera mundial y por particularidades muy propias de esa economía (alta tasa de sindicalismo y políticas monetarias y fiscales poco sanas).

El Ecuador estaba en un contexto internacional idéntico al de la Argentina, pero mantuvo una tasa de crecimiento bastante fluctuante y, en promedio, más baja con respecto a esa economía (véase el gráfico 6). Las razones se encuentran en las decisiones de política económica durante el período 2000-2006, que comprimían la demanda interna y, por supuesto, el régimen monetario. Se destaca que la distribución del ingreso se mantuvo alta e inalterable ${ }^{18}$.

Gráfico 6

Ecuador: tasa de crecimiento de la economía, 2001-2015a

(En porcentajes)

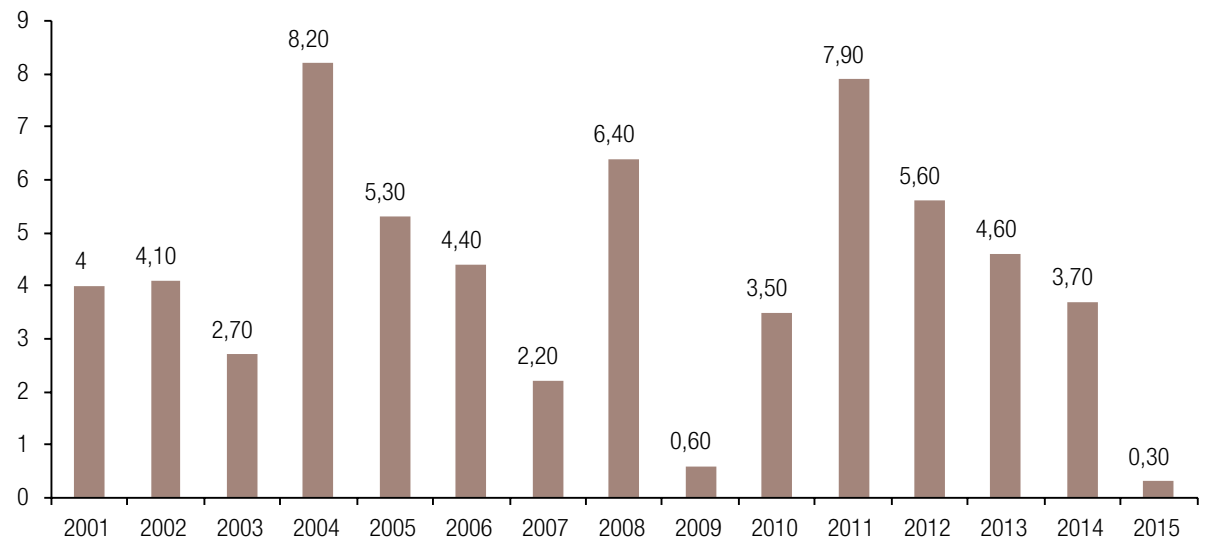

Fuente: Elaboración propia, sobre la base de datos del Banco Central del Ecuador (BCE), Información Estadística Mensual, № 1971, Quito, 2016.

a Año base $=2007$.

En una columna titulada "Inequality is holding back the recovery" ("La desigualdad frena la recuperación"), publicada el 19 de enero de 2013 en el diario The New York Times, Stiglitz señaló que antes nos preguntábamos hasta qué punto estábamos dispuestos a sacrificar el crecimiento a cambio de un poco más de igualdad y oportunidades; ahora nos damos cuenta de que estamos pagando un elevado precio por la desigualdad y que su mitigación y la promoción del crecimiento son metas entrelazadas y complementarias entre sí (Stiglitz, 2013). De la columna de Stiglitz surge que el postulado "primero crecer, después repartir" (que tantas veces defendieron los economistas de la recomposición neoliberal en el Ecuador) no se cumplió (como también quedó demostrado en el Ecuador en el período 2007-2013).

\footnotetext{
18 Pacheco (2009, pág. 53) explica que, en la época de la dolarización en el Ecuador (hasta 2006), se registra una profunda inestabilidad y desigualdad en el desarrollo, aunque con una relativa estabilidad de los precios. Según ese autor, el coeficiente de Gini fue de 0,58 en el período 2000-2005.
} 
Los crecimientos económicos más elevados desde la dolarización fueron en 2004 y 2011. No obstante, si esas tasas se analizan comparativamente, aportan resultados muy diferentes. En 2004, las actividades que más contribuyeron a la expansión de la economía fueron el petróleo y la extracción de recursos minerales, con un 41,7\% de crecimiento. En 2011, en cambio, las actividades que generaron más empleo fueron la acuicultura, la pesca de camarón y la construcción, con un $22,1 \%$ y un $21,6 \%$, respectivamente. La pesca creció un 6,2\% en 2011, mientras que en 2004 decreció un 9,7\% (véase el gráfico 7).

Gráfico 7

Ecuador: tasa de crecimiento del producto interno bruto (PIB) por sector económico, 2004 y $2011^{a}$

(En porcentajes)

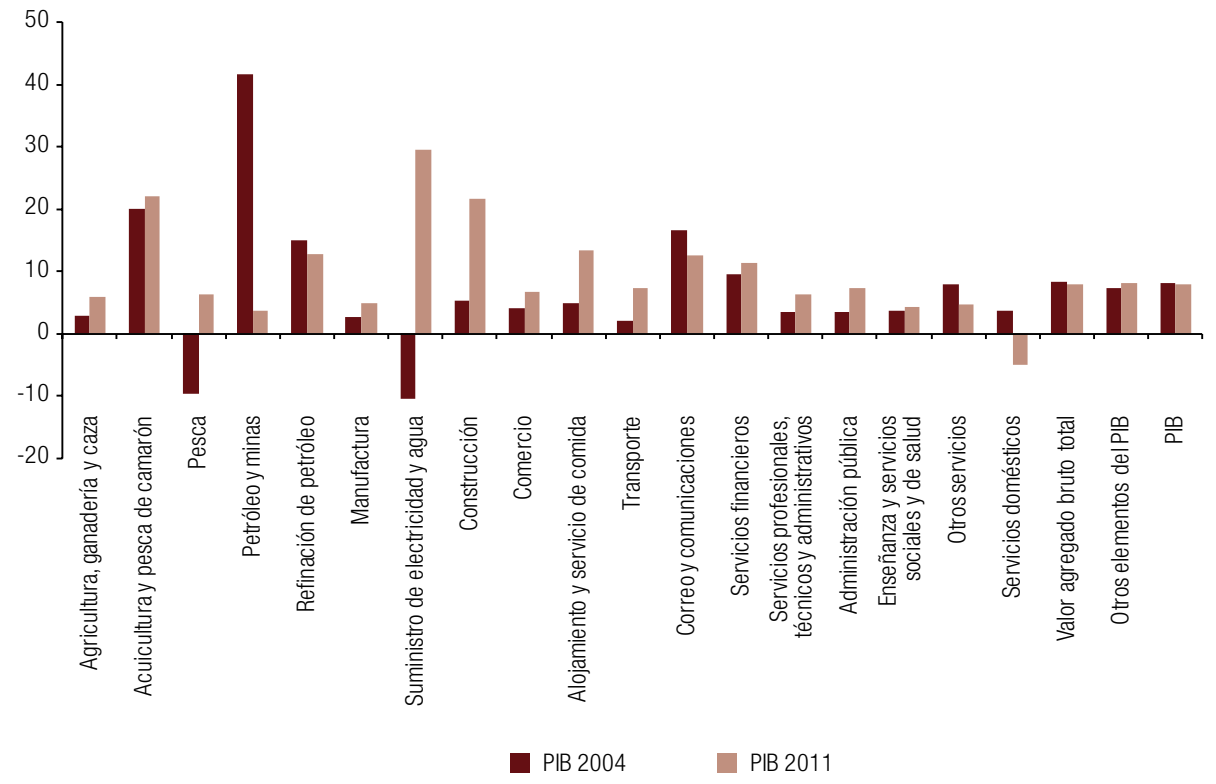

Fuente: Elaboración propia, sobre la base de datos del Banco Central del Ecuador (BCE), Información Estadística Mensual, No 1951, Quito, 2014.

a Año base $=2007$.

Lo importante no es solo crecer, sino también cómo se crece. Mientras que en 2004 se registraba una de las dos tasas de expansión económica más altas del período, no se reflejaban los efectos en la población, sobre todo en el coeficiente de Gini (que se mantuvo constante) y en la tasa de desempleo, que superaba el 9\% de la población económicamente activa ${ }^{19}$. En cambio, en 2011, el alto crecimiento vino de la mano de una mejora en la distribución de la riqueza: el tercer mejor coeficiente de Gini de la región, una tasa de desempleo cercana al 5\% y la mayor reducción de la pobreza y de la indigencia en América Latina. Concretamente, la indigencia se redujo por primera vez a cifras de un dígito $(9,4 \%)$ en junio de 2012 (CEPAL, 2012a y CEPAL, 2013) ${ }^{20}$.

Considerando que la dolarización (unilateral) del Ecuador no provee las condiciones óptimas para encauzar un intenso y sostenido proceso de acumulación de capital, y que constituye un régimen cambiario rígido, se señala lo siguiente:

19 Véase diario El Universo, "La macroeconomía no da de comer a los pobres" [en línea] [http://www.eluniverso.com/2005/05/0 1/0001/21/5DF504F40EFE4E329331EDA4EC230FE4.html.

${ }^{20}$ A septiembre de 2014, la tasa de desempleo se encontraba en su punto más bajo en todo el período de la dolarización (3,90\%). En esa misma fecha, la pobreza y la indigencia se ubicaban en un $24,75 \%$ y un $8,56 \%$, respectivamente, y el coeficiente de Gini (urbano) era de 0,4619. 
i) Desde el Departamento de Estudios del Fondo Monetario Internacional, Ghosh, Qureshi y Tsangarides (2013 y 2014) destacan que los tipos de cambio fijos obstaculizan el ajuste externo: los desequilibrios externos (superávits o déficits en cuenta corriente) son menos persistentes en regímenes de tipo de cambio flotante, lo que reduce la posibilidad de que se acumulen desequilibrios peligrosos que lleven a una crisis. Este argumento ya había sido elaborado por Milton Friedman en 1953 en su trabajo The case for flexible exchange rates.

ii) Rodrik (2008) demuestra la correlación entre crecimiento y tipo de cambio real. En palabras de Frenkel (2008), "aunque la magnitud y evolución del efecto del tipo de cambio real competitivo y estable sobre la demanda agregada sean difíciles de precisar, sabemos que el mayor crecimiento que experimentan las economías que lo adoptan resultan en parte de ese efecto".

iii) Cabría destacar la no neutralidad del dinero a corto y mediano plazo, postulada desde los años treinta por J.M. Keynes y los poskeynesianos, en otras palabras, la vinculación entre la esfera monetaria y la real (Guttmann, 1996).

iv) El concepto de no neutralidad también sería válido a largo plazo. Blanchard (2003) afirma que una política monetaria activa tiene efectos duraderos sobre la tasa de interés y, por consiguiente, en el desempleo. Un alza sostenida de la tasa de interés real provocará una elevada tasa de desempleo que, dada su duración, la disminución de la acumulación del capital y los efectos sobre el margen de beneficio de las empresas (mayores gastos financieros), llevará a que la tasa natural de desempleo se incremente. Una baja sostenida de la tasa de interés real tiene el recorrido inverso.

La iniciativa de crear grados de política monetaria en una economía sin moneda propia se basa en lo demostrado por Blanchard (2003). La repatriación de capitales practicada en el Ecuador desde 2009 (y la reducción de la tasa de interés activa) demuestra que no solo ayudó a sortear las perturbaciones de la crisis financiera internacional, sino que contribuyó a la disminución de la tasa natural de desempleo. Los ahorros de los depositantes en el exterior que regresaron al país no sirvieron para amortiguar una posible corrida de depósitos, sino para expandir el crédito privado y dinamizar la producción y el empleo.

\section{La condición principal de la nueva matriz productiva: la recuperación de la política cambiaria}

La última razón para salir de la dolarización es la construcción de una nueva matriz productiva. La experiencia de los tigres asiáticos (Hong Kong (Región Administrativa Especial de China), Indonesia, el Japón, Malasia, la provincia china de Taiwán, la República de Corea, Singapur y Tailandia ) revela la necesidad de que el tipo de cambio sea alto para promover las exportaciones, sobre todo de las industrias nacientes.

Frenkel (2008) y Frenkel y Rapetti (2009) afirman que el tipo de cambio competitivo es el que determina los incentivos para la producción de una amplia gama de productos comercializables en el ámbito internacional, con miras a su colocación en los mercados externo o interno. Además, sostiene que, a diferencia de otros sistemas de incentivos, esa política de promoción generalizada de las actividades comercializables (por encima de las no comercializables) no da lugar a la búsqueda de renta.

La insistencia de mantener al dólar como moneda nacional significaría depender de su debilidad a largo plazo, lo que es muy improbable. La actual desventaja de los precios relativos del Ecuador con su principal socio comercial (véanse los gráficos 4 y 5) es un grave problema para el sector exportador ecuatoriano, teniendo en cuenta, como expresan Falconí y Oleas (2004), que "la dolarización adolece de varios problemas medulares, el más grave es de orden estructural y afecta la economía del país en el largo plazo: la productividad". 


\section{Conclusiones y reflexiones finales}

Desde el anuncio y la implementación de la dolarización en el Ecuador, los representantes y partidarios de ese régimen monetario han tratado de blindarlo por todos los medios (económicos, políticos y sociales) ${ }^{21}$. Su principal instrumento fue crear en el imaginario social la imposibilidad de salida, porque cualquier intento de poner en duda ese régimen llevaría a la economía ecuatoriana al peor de los mundos.

En el Ecuador, en la década pasada, el fin último de la economía pasó del régimen monetario al ser humano, como eje de la sociedad. Ese cambio de concepción provocó (de forma indirecta) la subsistencia de la dolarización a lo largo del tiempo, ya que la estructura económica diseñada durante el período 2000-2006 habría provocado la caída del régimen monetario por los severos efectos de la crisis financiera de los países centrales, transmitidos por el canal comercial.

Entre 2000 y 2006, la clase dirigente financiera y económica del Ecuador creó leyes, normas e ideas para que todo esfuerzo de la sociedad asegure la subsistencia de la dolarización, aun cuando el ciclo sea decreciente. Asegurar esa subsistencia redundó en altas tasas de rentabilidad para los sectores ligados a ese régimen (y a sus políticas), por ello se habla de la existencia de una economía política de abandono de la moneda nacional.

Ese fin último en que se convirtió la dolarización no solo siguió postergando el desarrollo económico del país, sino que lo reprimió hasta el punto de convertirlo en un proceso político que se anunció como irreversible a partir de 2007. El desarrollo reprimido del Ecuador llevó a la transformación del modo de regulación mediante el cambio de sus formas institucionales y, posteriormente, del régimen de acumulación.

La transformación del modo de regulación empezó con la reorganización y reinstitucionalización del Estado en todo el territorio y prosiguió con las demás formas institucionales. El régimen de acumulación y el funcionamiento del capitalismo ecuatoriano también fueron transformados, bajo la premisa de que el ser humano es el fin último de la sociedad. No obstante, para que ese cambio no se revierta con facilidad es necesaria e indispensable la salida de la dolarización. El propio desarrollo económico, que impulsó la transformación del modo de regulación, exige la recuperación de la soberanía monetaria para profundizar esa transformación.

La dolarización ha tenido impactos estructurales en la distribución del poder en el Ecuador. La salida de ella también los tendría. Lo más conveniente sería implementarla en momentos en que la transformación del Estado y la relación salarial se encuentran en una posición dominante y en un contexto donde se está realizando una profunda distribución progresiva de los ingresos. De lo contrario, se dejaría abierta la puerta para que, como muy bien señala Acosta (2004), los grupos oligárquicos que ganaron con la dolarización lo vuelvan a hacer y para que los representantes de la economía "ortodoxa, conservadora y prudente" impulsen una salida amparada en los principios neoliberales.

\section{Bibliografía}

Acosta, A. (2004), “Dolarización o desdolarización, esa no es toda la cuestión!”, Íconos, №19, Quito, Facultad Latinoamericana de Ciencias Sociales (FLACSO).

Aglietta, M. (1979), Regulación y crisis del capitalismo, Ciudad de México, Siglo XXI.

${ }^{21}$ El último intento en ese sentido fue el de la Federación Interamericana Empresarial (FIE), en septiembre de 2014, cuando se planteó una ley de alianza público-privada con el objetivo de cambiar la política económica de los últimos seis años, concentrada en el alto gasto público. Otros dirigentes empresariales rechazaron la propuesta, argumentando que el Gobierno debía reducir el gasto público sin alianzas de ningún tipo. 
Altimir, O., L. Beccaria y M. González (2002), "La distribución del ingreso en Argentina, 1974-2000”, Revista de la CEPAL, № 78 (LC/G.2187-P), Santiago, Comisión Económica para América Latina y el Caribe (CEPAL).

Amable, B. (2007), "Los cincos capitalismos: diversidad de sistemas económicos y sociales en la mundialización", Revista de Trabajo, № 4, Buenos Aires.

Baldi-Delatte, A. (2007), "La adhesión de los argentinos a la nueva regla monetaria: el peso vencedor del dólar", Salidas de crisis y estrategias alternativas de desarrollo, R. Boyer y J.C. Neffa (coord.), Buenos Aires, Miño y Dávila.

BCE (Banco Central del Ecuador) (2016), Información Estadística Mensual, № 1971, Quito. (2014), Información Estadística Mensual, № 1951, Quito.

(2012), Cuentas Nacionales, № 24, Quito.

(2009), Información Estadística Mensual, № 1886, Quito.

Blanchard, O. (2003), "Monetary policy and unemployment" [en línea] http://economics.mit.edu/files/731.

Boyer, R. (2007), "Vigorosa recuperación... aunque incertidumbre sobre el nuevo régimen de crecimiento", Salidas de crisis y estrategias alternativas de desarrollo, R. Boyer y J.C. Neffa (coord.), Buenos Aires, Miño y Dávila.

Boyer, B. y T. Saillard (eds.) (1996), Teoría de la regulación: estado de los conocimientos, vols. 1, 2 y 3, Buenos Aires, Eudeba.

Calderón, G. (2009), "Dolarización: ser y parecer" [en línea] http://www.elcato.org/dolarizacion-ser-y-parecer.

Carrera, J. (2004), "Las lecciones de la caja de conversión de Argentina", La economía Argentina y sus crisis (1976-2001), R. Boyer y J.C. Neffa (coord.), Buenos Aires, Miño y Dávila.

CEPAL (Comisión Económica para América Latina y el Caribe) (2013), Panorama Social de América Latina 2012 (LC/G.2557-P), Santiago.

(2012a), Panorama Social de América Latina 2011 (LC/G.2514-P), Santiago.

(2012b), Inversión Extranjera Directa en América Latina y el Caribe 2011 (LC/G.2538-P), Santiago.

(2012C), Cambio estructural para la igualdad: una visión integrada del desarrollo (LC/G.2524(SES.34/3)), Santiago.

Conesa, E. (1996), Desempleo, precios relativos y crecimiento económico, Buenos Aires, Ediciones Depalma.

Coq, D. (2007), "Los regímenes monetarios con paridades irrevocablemente fijas: algunas reflexiones de la experiencia argentina", Revista Principios, № 7 , Sevilla.

Correa, R. (2004a), "Dolarización y desdolarización: más elementos para el debate. Comentarios al dossier de Iconos 19", Íconos, № 20, Quito, Facultad Latinoamericana de Ciencias Sociales (FLACSO). (2004b), "De absurdas dolarizaciones a uniones monetarias", ponencia presentada en el Seminario "Dolarización y alternativas", Quito, Universidad Andina Simón Bolívar.

Cuevas, V. (2002), "Alternativas de integración monetarias entre México, Estados Unidos y Canadá", Moneda y régimen cambiario en México, F.G. Chávez (coord.), Ciudad de México.

El Universo (2005), "La macroeconomía no da de comer a los pobres" [en línea] http://www.eluniverso.com /2005/05/01/0001/21/5DF504F40EFE4E329331EDA4EC230FE4.html.

Falconí, F. y J. Oleas (comp.) (2004), Economía ecuatoriana, Quito, FLACSO-Ecuador.

Ferrer, A. (2004), La economía argentina, Buenos Aires, Fondo de Cultura Económica (FCE).

FMI (Fondo Monetario Internacional) (2004), Informe sobre la evaluación del papel del FMI en Argentina, 1991-2001, Washington, D.C., Oficina de Evaluación Independiente.

(2003), "Ecuador-Letter of Intent, Memorandum of Economic and Financial Policies, and Technical Memorandum of Understanding" [en línea] http://www.imf.org/external/np/loi/2003/ecu/01/index.htm (2001), World Economic Outlook, Washington, D.C.

Frenkel, R. (2008), "Tipo de cambio real competitivo, inflación y política monetaria", Revista de la CEPAL, № 96 (LC/G.2396-P), Santiago.

Frenkel, R. y M. Rapetti (2009), "Flexibilidad cambiaria y acumulación de reservas en América Latina", Lecturas, $N^{\circ} 50$, Buenos Aires, Iniciativa para la Transparencia Financiera (ITF).

Friedman, M. (1953), "The case for flexible exchange rates", Essays in Positive Economics, Chicago, University of Chicago Press.

Fuentes, J.A. (ed.) (2014), Inestabilidad y desigualdad. La vulnerabilidad del crecimiento en América Latina y el Caribe, Santiago, Comisión Económica para América Latina y el Caribe (CEPAL).

Galiani, S., D. Heymann y M. Tomassi (2003), "Expectativas frustradas: el ciclo de la convertibilidad", serie Estudios y Perspectivas, № 16 (LC/BUE/L.185), Santiago, Oficina de la CEPAL en Buenos Aires. 
Ghosh, A., M. Qureshi y C. Tsangarides (2014), "Friedman Redux: external adjustment and exchange rate flexibility", IMF Working Paper, N WP/14/146, Washington, D.C., Fondo Monetario Internacional.

(2013), "Is the exchange rate regime really irrelevant for external adjustment?", Economics Letters, vol. 118, N 1, Amsterdam, Elsevier.

Guttmann, R. (1996), "Moneda y crédito en la teoría de la regulación", Teoría de la regulación: estado de los conocimientos, R. Boyer y T. Saillard (eds.), vols. 1, 2 y 3, Buenos Aires, Eudeba.

Heymann, D. (2000), "Políticas de reformas y comportamiento macroeconómico: la Argentina en los noventa", serie Reformas Económicas, № 61 (LC/L.1357), Santiago, Comisión Económica para América Latina y el Caribe (CEPAL).

Heymann, D. y A. Ramos (2010), "Una transición incompleta. Inflación y políticas macroeconómicas en la Argentina Post-convertibilidad", Revista de Economía Política de Buenos Aires, año. 4, vol. 7-8, Buenos Aires.

INDEC (Instituto Nacional de Estadística y Censos) (varios años), "Encuesta Permanente de Hogares (EPH)", Buenos Aires.

Jameson, K. (2003), "Is it possible to de-dollarize?", International Journal of Political Economy, vol. 33, № 1, Taylor \& Francis.

Keifman, S. (2004), "Auge y derrumbe de la convertibilidad argentina: lecciones para Ecuador", Íconos, № 19, Quito, Facultad Latinoamericana de Ciencias Sociales (FLACSO).

Marconi, S. (ed.) (2001), Macroeconomía y economía política en dolarización, Quito, Ediciones Abya-Yala/ Instituto Latinoamericano de Investigaciones Sociales (ILDIS)/Universidad Andina Simón Bolívar.

Marques-Pereira, J. (2007), "Crecimiento, conflicto distributivo y soberanía monetaria en Argentina”, Salidas de crisis y estrategias alternativas de desarrollo, B. Boyer y J.C. Neffa (coords.), Buenos Aires, Miño y Dávila.

Martirena-Mantel, A. (2003), "Sobre la creación de áreas monetarias óptimas. El aporte de Robert Mundell", Económica, vol. 40, Universidad Nacional de la Plata.

Miño, W. (2008), Breve historia bancaria del Ecuador, Quito, Corporación Editora Nacional.

Naranjo, M. (2004), "Costos del abandono de la dolarización en el Ecuador", Íconos, № 19, Quito, Facultad Latinoamericana de Ciencias Sociales (FLACSO).

Naranjo, M. y L. Naranjo (2011), "Costos y escenarios de la salida de la dolarización oficial en el Ecuador", Revista de la Facultad de Economía de la PUCE, Quito, Pontificia Universidad Católica de Quito (PUCE).

Oleas, J. (2001), "Del libertinaje financiero a la pérdida del signo monetario: una visión macroeconómica", Macroeconomía y economía política en dolarización, S. Marconi (ed.), Quito, Abya-Yala/Instituto Latinoamericano de Investigaciones Sociales (ILDIS)/Universidad Andina Simón Bolívar.

Pacheco, L. (2009), "El caso de Ecuador: la política económica del Gobierno de Rafael Correa", Nuevas políticas económicas de izquierda en América Latina, S. Lichtensztejn (comp.), Veracruz, Biblioteca Universidad Veracruzana.

Paredes, G.J. (2015), Integraciones monetarias pasivas en Sudamérica, Buenos Aires, Ediciones Cooperativas.

Rodrik, D. (2008), "The real exchange rate and economic growth", Brookings Papers on Economic Activity, vol. 39, № 2, Washington, D.C., The Brookings Institution.

Roig, A. (2007), "La confianza desesperada: discurso científico y crisis monetaria", Salidas de crisis y estrategias alternativas de desarrollo, B. Boyer y J.C. Neffa (coords.), Buenos Aires, Miño y Dávila.

Sánchez, J. (2011), "Equidad y políticas sociales. Algunas reflexiones para el caso ecuatoriano", A. Serrano, (coord.), iA (Re)DISTRIBUIR!: Ecuador para todos, Quito, Secretaría Nacional de Planificación y Desarrollo (SENPLADES).

Schuler, K. (2003), “¿Qué sucedió en Argentina?”, Washington D.C., Cato Institute [en línea] http://www. elcato.org/que-sucedio-en-argentina.

Spurrier, W. (2013), "Las economías de Guayaquil y Quito", El Universo [en línea] http://www.eluniverso.com/ opinion/2013/08/11/nota/1269991/economias-guayaquil-quito.

Stiglitz, J. (2013), "Inequality is holding back the recovery", The New York Times, 19 de enero. (2012), El precio de la desigualdad, Madrid, Taurus.

Wainer, A. (2010), "Clase dominante, hegemonía y modos de acumulación. La reconfiguración de las relaciones de fuerza en el interior de la burguesía durante la crisis y salida de la convertibilidad (1998-2003)", tesis para optar al grado de doctorado, Buenos Aires, FLACSO-Argentina. 